\title{
The Influence of Wine Polyphenols on Reactive Oxygen and Nitrogen Species Production by Murine Macrophages RAW 264.7
}

\author{
M. Číž, M. PAVELKOVÁ, L. GALLOVÁ, J. KRÁLOVÁ, L. KUBALA, A. LOJEK \\ Institute of Biophysics, Academy of Sciences of the Czech Republic, Brno, Czech Republic
}

Received August 14, 2008

Accepted February 27, 2008

On-line April 25, 2007

\begin{abstract}
Summary
The aim was to study the antioxidant properties of four wine polyphenols (flavonoids catechin, epicatechin, and quercetin, and hydroxystilbene resveratrol). All three flavonoids exerted significant and dose-dependent scavenging effects against peroxyl radical and nitric oxide in chemical systems. The scavenging effect of resveratrol was significantly lower. All polyphenols decreased production of reactive oxygen species (ROS) by RAW264.7 macrophages. Only quercetin quenched ROS produced by lipopolysaccharide-stimulated RAW264.7 macrophages incubated for $24 \mathrm{~h}$ with polyphenols. Quercetin and resveratrol decreased the release of nitric oxide by these cells in a dose-dependent manner which corresponded to a decrease in iNOS expression in the case of quercetin. In conclusion, the higher number of hydroxyl substituents is an important structural feature of flavonoids in respect to their scavenging activity against ROS and nitric oxide, while C-2,3 double bond (present in quercetin and resveratrol) might be important for inhibition of ROS and nitric oxide production by RAW 264.7 macrophages.
\end{abstract}

\section{Key words}

Antioxidants • Polyphenols $\bullet$ Macrophages $\bullet$ Oxidative stress $\bullet$ Nitric oxide

\section{Corresponding author}

Milan Číz, Institute of Biophysics, Academy of Sciences of the Czech Republic, Královopolská 135, 61265 Brno, Czech Republic. Fax: +420-541211293. E-mail: milanciz@ibp.cz

\section{Introduction}

The overproduction of reactive oxygen and nitrogen species (ROS and RNS, respectively) by phagocytes causes oxidative damage to membrane lipids, DNA, proteins and lipoproteins. These reactions have functional consequences, which may be deleterious to cells and tissues. Thus, the inhibition of ROS and RNS production is a popular target for the attenuation of many inflammatory diseases (Shen et al. 2002).

Dietary polyphenols with antioxidative effects from fruit and vegetables play an important role in a prevention of the oxidative stress (Mojžišová and Kuchta 2001, Osawa 1999). Another important source of polyphenolic antioxidants is wine, particularly red wine. It has been demonstrated that polyphenols from wine have not only antioxidative but also anti-inflammatory effects (Oak et al. 2005) and that they can prevent cardiovascular diseases (Babal et al. 2006). It is furthermore suggested that they prevent free radicalmediated lipid peroxidation of low density lipoproteins (LDL), which is associated with cell aging and chronic disesases such as atherosclerosis (Dell'Agli et al. 2004, Cook and Samman 1996, Oak et al. 2005, Rajdl et al. 2006). It is postulated that the antioxidant and free radical scavenging properties of phenolic compounds, present in red wine, may partly explain the "French paradox", i.e. the fact that French people have low incidence of coronary heart disease, despite having a diet high in fat and being heavy smokers (Aruoma 1994). The main polyphenolic compounds in red wine belong to two major classes: flavonoids and stilbenes. Of the flavonoids, $(+)-$ catechin, (-)-epicatechin and quercetin and of the stilbenes, trans-resveratrol, are the most abundant polyphenols in wine. Exact mechanisms by which flavonoids protect against oxidative stress-mediated diseases (such as atherosclerosis) are still a matter of debate (Benito et al. 2004).

The aim of this experiment was to study the antioxidant properties of four wine polyphenols (catechin 
- CAT, epicatechin - EPI, quercetin - QUE, resveratrol RES) against peroxyl radical and nitric oxide, their immediate and long-term effects on the production of reactive oxygen and nitrogen species by RAW 264.7 macrophages, and their influence on the expression of inducible nitric oxide synthase. Special attention was paid to differentiate between scavenging and inhibiting activity of the studied polyphenols with respect to their chemical structure. As far as we know, there are no similar investigations on the same selection of polyphenols, especially concerning the effects of polyphenols on various parameters linked to the generation of nitric oxide. The advantage of the study is that it took into consideration many factors: kind and dose of polyphenols, time of their action, and different reactive metabolites.

\section{Methods}

\section{Materials}

Murine RAW 264.7 macrophage cell line was obtained from the American Type Culture Collection (ATCC, Manassas, Virginia, USA). Cells were maintained in a Dulbecco's Eagle medium (DMEM) (Sigma-Aldrich, St. Louis, Missouri, USA) supplemented with a $10 \%$ fetal bovine serum, gentamycin $(0.045 \mathrm{mg} / \mathrm{l})$, glucose $(3.5 \mathrm{~g} / \mathrm{l})$ and $\mathrm{NaHCO}_{3}(1.5 \mathrm{~g} / \mathrm{l})$. The stock solution of lipopolysaccharide (LPS) from Escherichia coli serotype 0111:B4 (Sigma-Aldrich, St. Louis, Missouri, USA) was made up at $10^{-3} \mathrm{~g} / 1$ in Hanks' balanced salt solution without phenol red (HBSS, $\mathrm{pH}$ 7.4). The final concentration of LPS in a reaction mixture was $10^{-7} \mathrm{~g} / \mathrm{l}$. Polyphenols (CAT, EPI, QUE and RES) were purchased from Sigma-Aldrich (St. Louis, Missouri, USA). Stock solutions $\left(2 \times 10^{-2} \mathrm{~mol} / \mathrm{l}\right)$ were always prepared fresh, in $99.8 \%$ ethanol. Then, concentrations of $2 \times 10^{-4}, 5 \times 10^{-4}, 1 \times 10^{-3}, 2 \times 10^{-3} \mathrm{~mol} / 1$ were prepared in RPMI 1640 and added to the reaction mixture to obtain final concentrations of $10^{-5}, 2.5 \times 10^{-5}, 5 \times 10^{-5}$ and $10^{-4}$ mol/1, respectively.

ABAP [2,2-azo-bis(2-amidinopropane) hydrochloride] was purchased from Polyscience (Warrington, Pennsylvania, USA) and Trolox (6-hydroxy-2,5,7,8,tetramethyl-chroman-2-carboxylic acid) from SigmaAldrich (St. Louis, Missouri, USA). The stock solution of $10^{-2} \mathrm{~mol} / 1$ luminol (5-amino-2,3-dihydro-1,4-phthalazinedione) (Molecular Probes, Eugene, Oregon, USA) was prepared in $0.2 \mathrm{~mol} / 1$ sodium borate buffer, $\mathrm{pH} 9.0$ (1.24 $\mathrm{g}$ of $\mathrm{H}_{3} \mathrm{BO}_{3}$ and $7.63 \mathrm{~g}$ of $\mathrm{Na}_{2} \mathrm{~B}_{4} \mathrm{O}_{7} \cdot 10 \mathrm{H}_{2} \mathrm{O}$ in one liter of redistilled water). All other reagents were purchased from Sigma-Aldrich (St. Louis, Missouri, USA). PMA (phorbol 12-myristate 13-acetate) was dissolved in dimethylsulphoxide to obtain $3 \times 10^{-3} \mathrm{~mol} / 1$ stock solution.

\section{Total radical-trapping antioxidant parameter (TRAP)}

The luminol-enhanced chemiluminescence (CL) assay for TRAP was measured using a Luminometer 1251 (BioOrbit, Turku, Finland). The method is based on the measurement of peroxyl radicals produced at a constant rate by a thermal decomposition of ABAP. The TRAP value is determined from the time period during which the CL signal is diminished by antioxidants (Slavíková et al. 1998). Trolox, a water-soluble analogue of $\alpha$-tocopherol, was used as a reference inhibitor for the calculation of the TRAP value.

The reaction mixture contained $475 \mu$ of sodium phosphate buffered saline (PBS $10^{-1} \mathrm{~mol} / \mathrm{l}, \mathrm{pH} 7.4$ ), $50 \mu \mathrm{l}$ of $10^{-2} \mathrm{~mol} / 1$ luminol in $10^{-1} \mathrm{~mol} / 1$ borate buffer (pH 10.0), and $20 \mu \mathrm{l}$ of examined compound. The cuvettes were incubated at $37^{\circ} \mathrm{C}$ in the temperaturecontrolled carousel of the luminometer for $10 \mathrm{~min}$. Then, $50 \mu \mathrm{l}$ of $4 \times 10^{-1} \mathrm{~mol} / \mathrm{l}$ ABAP (prepared in $10^{-1} \mathrm{~mol} / \mathrm{l} \mathrm{PBS}$ ) was added. TRAP value for the sample was obtained from the equation: TRAP $=\mathrm{n}[$ Trolox $] \tau_{\text {sample }} / f \tau_{\text {Trolox }}$, where $\mathrm{n}$ is the stoichiometric factor of Trolox (2.0), $\tau$ is the time period of diminished chemiluminescence, and $f$ is the dilution factor of the sample.

\section{Scavenging of nitric oxide}

Tested compounds were diluted to reach final concentrations of $10^{-5}-10^{-4} \mathrm{~mol} / \mathrm{l}$ in a final volume of $10 \mathrm{ml}$ of PBS. $1 \mu \mathrm{l}$ of saturated nitric oxide solution was added and the concentration of nitric oxide was measured amperometrically using the ISO-NO Mark II isolated nitric oxide meter and ISO-NOP sensor (both from WPI, Sarasota, FL, USA). The method is based on a diffusion of NO through a selective membrane covering the sensor and its oxidation at the working electrode, resulting in an electrical current. The scavenging effect of tested compounds was evaluated based on a decrease in NO concentration in reaction mixture as compared to the control. The data are expressed as a redox current in pA.

\section{Experimental design}

When the immediate effect of polyphenols was studied, $2 \times 10^{5}$ of RAW 264.7 cells in $100 \mu$ of DMEM were allowed to adhere for $60 \mathrm{~min}$ to the edge of each of 
the 96-well plate and then all chemicals were added immediately before CL was measured.

When the long-term effect was studied, 96-well cultivation plates $\left(2 \times 10^{5}\right.$ cells per well) and 6-well cultivation plates $\left(2 \times 10^{6}\right.$ cells per well) were used for $\mathrm{CL}$ measurement and Western-blot analysis (and Griess reaction), respectively. Adhered cells ( $1 \mathrm{~h})$ were preincubated with one of the polyphenols at an indicated concentration for $1 \mathrm{~h}$ prior to the $24 \mathrm{~h}$ of incubation with LPS $\left(10^{-4} \mathrm{~g} / \mathrm{l}\right)$. Adherence as well as incubation steps proceeded at $37{ }^{\circ} \mathrm{C}$ with $5 \% \mathrm{CO}_{2}$. After $24 \mathrm{~h}$ the 96 -wells were gently washed with HBSS and CL was measured (as described below). The supernatants of the 6-well plates were removed and used for the determination of nitrites by Griess reaction as described below. Cells were used for a Western-blot analysis as described below.

\section{Chemiluminescence assay}

The luminol-enhanced CL of RAW 264.7 macrophages was measured using microtitre plate Luminometer LM-01T (Immunotech, Prague, Czech Republic) as described previously (Lojek et al. 1997). The principle of the method is based on a luminol interaction with the phagocyte-derived ROS, which results in large measurable amounts of light. Each well (in 96-well culture plates) contained $2 \times 10^{5}$ RAW 264.7 cells, luminol (at a final concentration of $10^{-3} \mathrm{~mol} / \mathrm{l}$ ) and PMA (at a final concentration of $8 \times 10^{-7} \mathrm{~mol} / \mathrm{l}$ ), which was selected on the basis of previous results (Lojek et al. 1997) and one of the polyphenols at final concentrations of $0,10^{-5}, 2.5 \times 10^{-5}, 5 \times 10^{-5}$ and $10^{-4} \mathrm{~mol} / 1$. The total reaction volume of $250 \mu \mathrm{l}$ was adjusted with HBSS. The assays were run in duplicates. Light emission expressed as relative light units (RLU) was recorded continuously at $37{ }^{\circ} \mathrm{C}$ for $60 \mathrm{~min}$. Intensity of the $\mathrm{CL}$ reaction is expressed as the integral of the obtained kinetic curves which correspond to the total amount of light produced during the time of measurements.

\section{Determination of nitric oxide}

The production of nitric oxide (NO) was estimated indirectly as the accumulation of nitrites $\left(\mathrm{NO}_{2}{ }^{-}\right)$, the metabolic end-product of $\mathrm{NO}$ metabolism, in the medium using the Griess reagent as described previously (Migliorini et al. 1991). Sodium nitrite was used as a standard. $150 \mu \mathrm{l}$ of culture supernatant was added to $150 \mu \mathrm{l}$ of Griess reagent (Sigma-Aldrich, St. Louis, Missouri, USA), then incubated for $15 \mathrm{~min}$ in a dark at room temperature and absorbance was measured at $532 \mathrm{~nm}$ on a SLT Rainbow spectrophotometer (Tecan, Crailsheim, Germany).

\section{Detection of inducible nitric oxide synthase (iNOS) by Western blot}

Cells were washed with cold PBS, scraped and then lysed in the lysis buffer (1 \% sodium dodecyl sulphate - SDS, $10^{-1} \mathrm{~mol} / 1$ Tris $\mathrm{pH} 7.4,10 \%$ glycerol, $10^{-3} \mathrm{~mol} / \mathrm{l}$ sodium ortho-vanadate, $10^{-3} \mathrm{~mol} / \mathrm{l}$ phenylmethanesulfonyl fluoride). Protein concentrations were measured with the DC protein assay (Bio-Rad, Hercules, California, USA) using bovine serum albumin as a standard. Equal amounts of proteins $(20 \mu \mathrm{g})$ were applied on SDS-polyacrylamide gel electrophoresis. Proteins were electrically transferred from the gel to a nitrocelulose membrane and immunoblotted with rabbit antiserum against the murine iNOS (Transduction Lab, Lexington, Kentucky, USA). Horseradish peroxidaseconjugated with anti-rabbit $\mathrm{IgG}$ antibody was used as a secondary antibody. The blots were visualized using ECL+ kit (Amersham, Arlington Heights, Illinois, USA) and exposed to CP-B X-ray films (Agfa, Brno, Czech Republic).

\section{Viability}

Viability was set using ATP kit SL (BioThema AB, Hanince, Sweden) on microtitre plate Luminometer LM-01T (Immunotech, Prague, Czech Republic).

\section{Statistical analysis}

All experiments were done in duplicates and repeated six times. All data are reported as means \pm S.E.M. The data were analyzed using the non-parametric Wilcoxon test or one-way analysis of variance (ANOVA) using Statistica for windows 5.0 (Statsoft, USA). $P \leq 0.01$ value was considered to be significant.

\section{Results}

\section{Immediate effect of polyphenols}

The total antioxidant capacity of four polyphenols studied (CAT, EPI, QUE and RES) measured as the ability to scavenge chemicaly generated peroxyl radical is shown in Figure 1. All polyphenols showed a significant antioxidant capacity, which increased in a dose-dependent manner. Flavonoids (CAT, EPI, QUE) were observed to show an approximately fourfold higher antioxidant capacity than hydroxystilbene RES. 

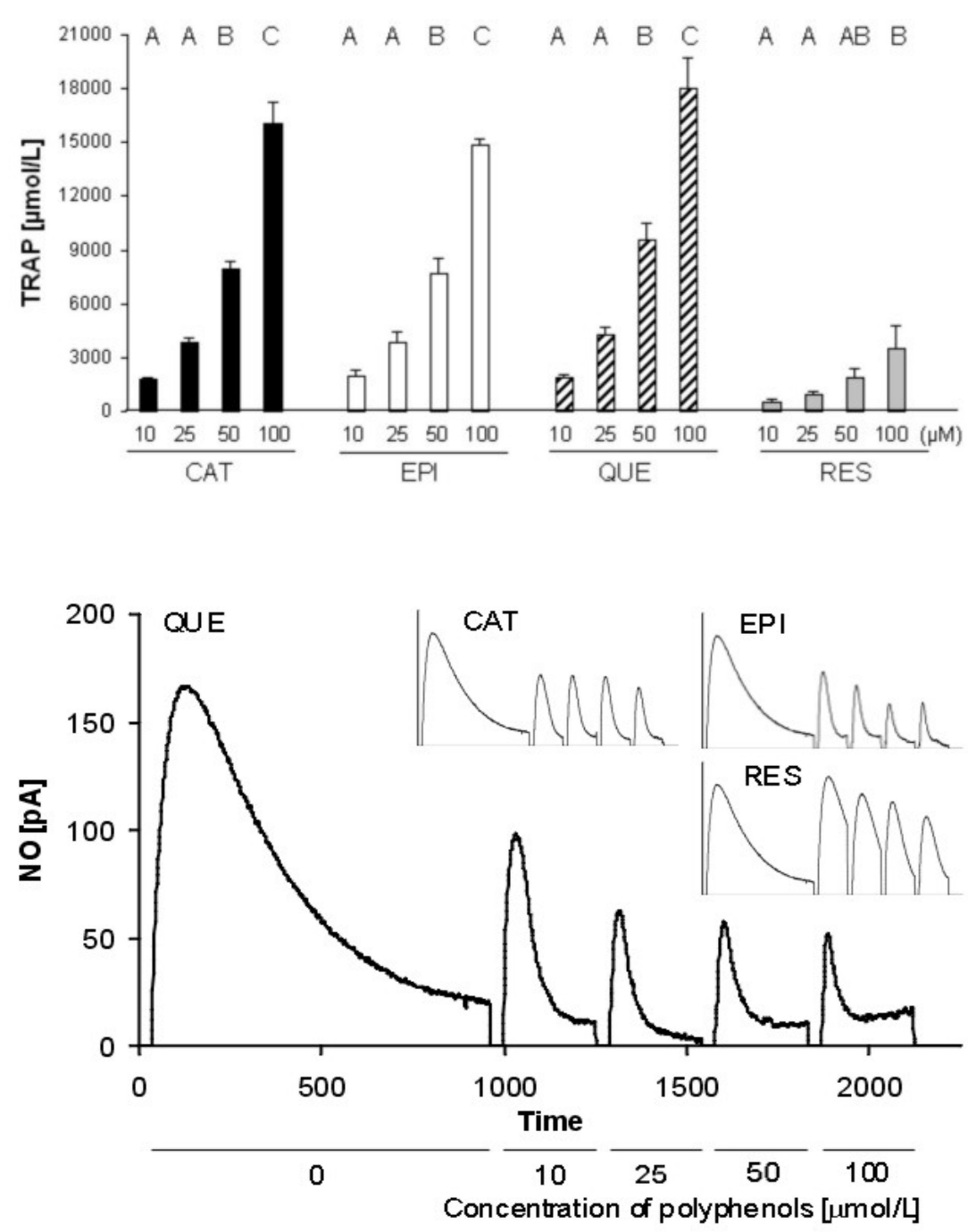

Fig. 1. Total antioxidant capacity of polyphenols. TRAP is expressed as $\mu \mathrm{mol}$ of the peroxyl radical trapped per one liter of polyphenolic solution. The changes of the parameter were found to be significant at the level of $p=0.01$ using ANOVA test. Statistically significant contrasts between the values are marked by different capital letters.
Fig. 2. The ability of polyphenols to scavenge NO determined ampero-metrically in a chemical system. The concentration of $\mathrm{NO}$ is expressed as a redox current in picoampers $(\mathrm{pA})$.
Similar results were obtained when the ability of tested compounds to scavenge nitric oxide was evaluated. Flavonoids (CAT, EPI, and especially QUE) were observed to markedly scavenge NO. However, resveratrol scavenged NO only mildly in the highest tested concentration (Fig. 2).

The ability of polyphenols to reduce the oxidative stress caused by biologically generated radicals was studied using murine macrophages RAW 264.7. All polyphenols dose-dependently inhibited the chemiluminescence produced by the PMA-stimulated RAW 264.7 (Fig. 3). The effect of RES was the highest among all compounds tested, because even the lowest concentration markedly inhibited chemiluminescence. Thus, RES seems to be a more potent inhibitor of the oxidative burst than flavonoids.

\section{Long-term effect of polyphenols}

LPS $\left(10^{-4} \mathrm{~g} / 1\right)$ increased the ROS production by
$190 \%\left(51.2 \times 10^{4}\right.$ vs. $17.6 \times 10^{4}$ RLU in untreated controls), as measured by PMA-activated CL. CAT, EPI and RES did not have any inhibitory effect on ROS production (data not shown). Conversely, QUE significantly decreased the ROS production of LPSstimulated RAW 264.7 in a dose-dependent manner (Fig. 4A).

LPS evoked a 30-fold induction of nitrite production as opposed to the untreated control $\left(34.4 \times 10^{-6}\right.$ vs. $1.1 \times 10^{-6} \mathrm{~mol} / 1 \mathrm{NO}_{2}^{-} / 2 \times 10^{6}$ cells, respectively). This induction was inhibited by QUE $\left(2.5 \times 10^{-5}-10^{-4} \mathrm{~mol} / \mathrm{l}\right)$ treatment in a dose-dependent manner (Fig. 4B). RES at concentrations of $5 \times 10^{-5}$ and $10^{-4} \mathrm{~mol} / 1$ cut the NO production by 7 and $26 \%$, respectively. However, no significant inhibition by CAT and EPI was found (data not shown).

The cytotoxicity of polyphenols in RAW 264.7 cells was examined by luminometrical detection of ATP concentration. None of the polyphenols affected the 

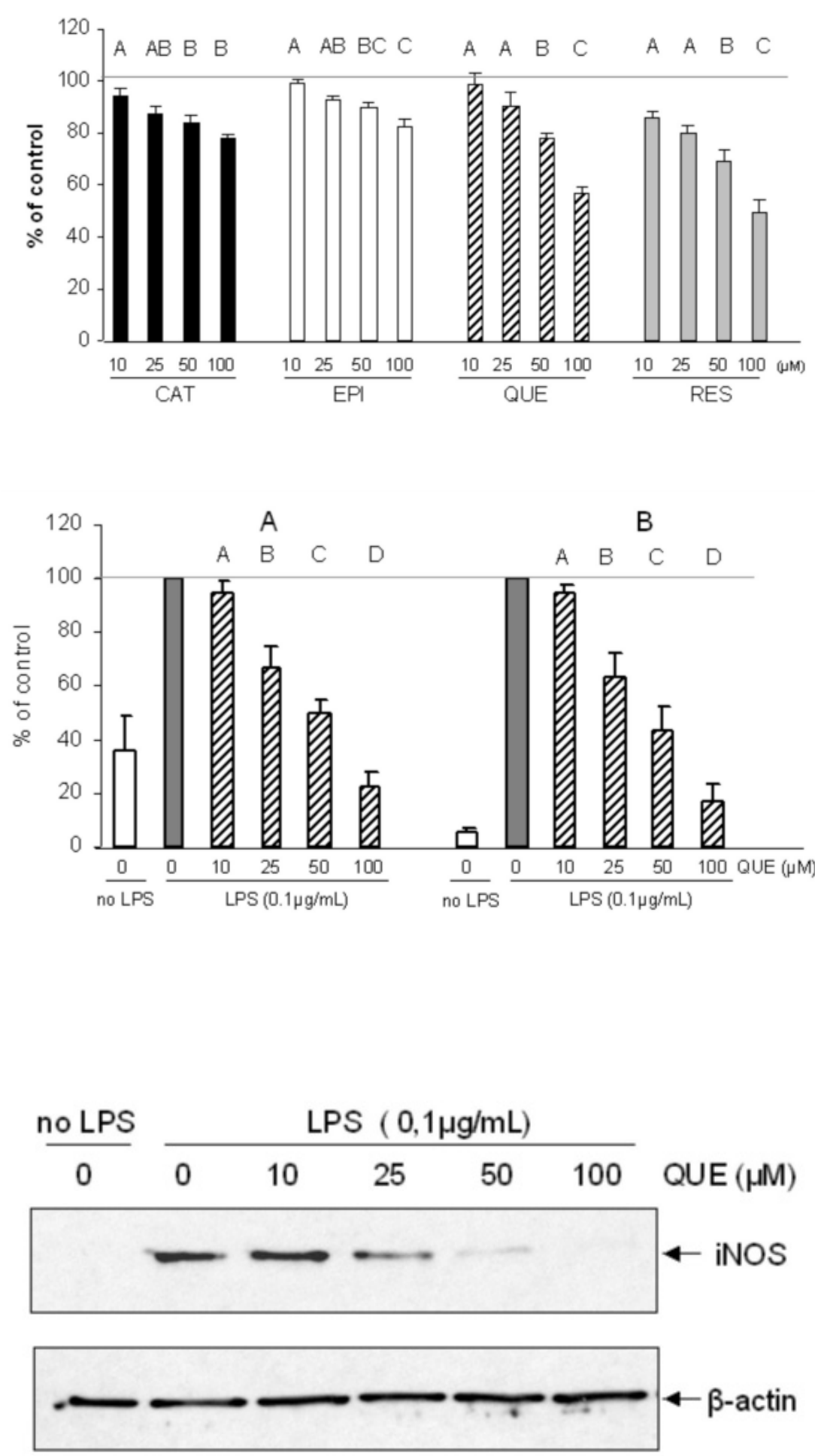

Fig. 3. Activity of polyphenols to scavenge reactive metabolites produced by RAW 264.7 cells (measured by chemiluminiscence). The changes of the parameter were found to be significant at the level of $p \leq 0.01$ using Wilcoxon test. Statistically significant difference between the values are marked by different capital letters.

Fig. 4. The effect of quercetin (QUE) on chemiluminescence activity and nitrite production by RAW 264.7 cells. Cells were pretreated with the indicated concentrations of QUE for $1 \mathrm{~h}$ before being incubated with LPS $\left(10^{-4} \mathrm{~g} / \mathrm{l}\right)$ for $24 \mathrm{~h}$. Control cells were incubated with vehicle alone. The changes of the parameter were found to be significant at the level of $p \leq 0.01$ using Wilcoxon test. Statistically significant contrasts between the values are marked by different capital letters. (A) Inhibition of reactive metabolite production by QUE in LPS-stimulated RAW 264.7 macrophages. Before measurement, supernatant was removed and cells were washed twice with PBS. Phorbol-myristate acetate was used to activate the oxidative burst of RAW 264.7 measured by chemiluminiscence. (B) Inhibition of nitrite production by QUE in LPS-stimulated RAW 264.7 cells. The cultured supernatants were subsequently isolated and analyzed for nitrite production.

Fig. 5. Inhibition of iNOS protein expression by QUE. Cultures were set up as described in the legend to Fig. 4. Equal loading of proteins was verified by $\beta$-actin immunoblotting. One of three representative experiments is shown. viability of RAW 264.7 cells (data not shown).

In view of the involvement of iNOS in the inflammatory process, we monitored iNOS protein expression by Western blot in RAW 264.7 exposed to polyphenols. As shown in Figure 5, expression of the iNOS protein was not detectable in unstimulated cells, but markedly increased $24 \mathrm{~h}$ after LPS $\left(10^{-4} \mathrm{~g} / \mathrm{l}\right)$ treatment. Treatment with QUE showed a concentration- dependent inhibition of iNOS protein expression in LPSstimulated RAW 264.7 cells. CAT, EPI and RES did not influence iNOS expression in LPS-activated RAW 264.7 cells (data not shown).

\section{Discussion}

In our paper, four wine polyphenols (CAT, EPI, 
QUE and RES) were studied from the viewpoint of their antioxidant capacity, their ability to scavenge biologically produced ROS and RNS and their influence on nitric oxide production and iNOS expression. Concentrations of polyphenols used in our experiments ranged between $10^{-4}-10^{-5} \mathrm{M}$ which corresponded to the red wine content of individual compounds: $191 \mathrm{mg} / 1\left(6 \times 10^{-4} \mathrm{M}\right) \mathrm{CAT}$, $82 \mathrm{mg} / \mathrm{l}\left(3 \times 10^{-4} \mathrm{M}\right) \mathrm{EPI}, 8-16 \mathrm{mg} / 1\left(2.5-5.0 \times 10^{-5} \mathrm{M}\right)$ QUE, and 1-8 mg/l (0.5-3.5 x 10-5 M) RES (Pendurthi and Rao 2002). The knowledge of absorption, biodistribution and metabolism of polyphenols is partial and incomplete. Some polyphenols are bioactive compounds that are absorbed from the gut in their native or modified form. They are subsequently metabolized to products detected in the plasma and then excreted. At concentrations found in vivo in human plasma (low nanomolar range), the effect of polyphenols is negligible in comparison with endogenous protection mechanisms against oxidative stress (Huisman et al. 2004).

In agreement with other authors (Cuendet et al. 2000, Nakao et al. 1998, Scott et al. 1993) we observed a significant antioxidant capacity against peroxyl radical of all studied polyphenols. Some authors have even found that QUE and CAT showed a greater efficacy to scavenge peroxyl radical on a mole to mole basis than the antioxidant nutrients vitamin $\mathrm{C}$, vitamin $\mathrm{E}$, and betacarotene (Rice-Evans 1995). In our study, flavonoids (CAT, EPI, QUE) showed an approximately four-fold higher ability to scavenge peroxyl radical than hydroxystilbene RES. The antioxidant potential of polyphenols depends on the number and arrangement of the hydroxyl groups and the extent of structure conjugation (Robak et al. 1988). They can donate hydrogen atom from their hydroxyl groups and stabilize the phenoxy radical formed by delocalization of the unpaired electron within the aromatic structure. It is wellknown that aromatic compounds containing hydroxyl groups, especially those having an O-dihydroxy group on ring $\mathrm{B}$, appear to be important scavengers as reported for flavonoids (Fauconneau et al. 1997). RES, a stilbene, is also known to have a strong antiradical activity, which is due to the presence of a conjugated double bond, which makes the electrons more delocalized (Khanduja and Bhardwaj 2003). The higher TRAP of flavonoids found in our experiments may be caused by the fact that flavonoids contain multiple hydroxyl groups (five $\mathrm{OH}$ groups) in comparison to RES (three $\mathrm{OH}$ groups), which are able to donate hydrogen atoms to peroxyl radicals and so have a greater potential to act as a scavenger of peroxyl radicals. This is also supported by the findings of López et al. (2003), who reported QUE to have higher antioxidant capacity against peroxyl radical than RES. On the other hand, Yilmaz and Toledo (2004) found the RES to be a more potent scavenger of chemically generated peroxide radicals than CAT and EPI.

Since cellular systems generate a variety of radicals including superoxide, hydroxyl and peroxyl radicals, nitric oxide and peroxynitrite, other experiments were performed to demonstrate the ability of flavonoids and RES to scavenge biologically generated radicals.

All tested compounds dose-dependently scavenged the free radicals that were produced by the PMA-stimulated RAW 264.7 cells. RES, interestingly, seems to be a more potent scavenger, although its TRAP was the lowest. The efficiency of individual polyphenols to scavenge peroxyl radical and inhibit the oxidative burst in macrophages was not always the same because of a different specificity of a polyphenol to scavenge peroxyl radical particularly and other free radicals involved in the process of an oxidative burst of macrophages. The TRAP test provides information on the reactivity of phenolic compounds with only one radical in a buffered solution. On the other hand, in the PMA-stimulated macrophage CL assay, a combination of many ROS is present. Moreover, the mechanisms of flavonoid actions may differ from that of stilbenes. In addition to their antioxidative properties, some polyphenols act as metal chelating agents and inhibit the superoxide-derived Fenton reaction, which is an important source of the most reactive hydroxyl radicals. Various authors consider chelation of metal ions as the main mechanism of polyphenolic action (Iwahashi 2000, Morel et al. 1994), while others consider ROS scavenging to dominate in the antioxidant effects (Fremont et al. 1999). Belguendouz et al. (1997) reported that RES protects LDL against peroxidative degradation mainly by chelating copper whereas flavonoids are better scavengers of free radicals. The ability to inhibit the Fenton reaction could explain the effectiveness of RES against biologically generated radicals in contrast to the system, where radicals are chemically produced in a copper-free buffered solution.

All phenomena previously described are responsible for a short-term response mediated by wine polyphenols. Recent studies have pointed out that polyphenolic compounds from several sources may also have long-term effects, as they are able to modulate gene expression in different transformed cell lines and in macrophages (Dell'Agli et al. 2004). We used a bacterial 
LPS for the induction of inflammation processes in RAW 264.7. LPS, as an outer membrane component of bacteria, triggers the generation of reactive oxygen intermediates as well as the secretion of a variety of inflammatory mediators, such as nitric oxide. In our experiment, a $190 \%$ increase in ROS production was observed when RAW 264.7 cells were incubated with LPS (24 h) in comparison with an untreated control. The incubation of cells with QUE diminished their LPS-activated production of ROS in a concentration-dependent manner (Fig. 4A). We found that QUE, in a concentration of $10^{-4}$ $\mathrm{mol} / \mathrm{l}$, reduced the ROS release even to the level of nonLPS-treated cells. Conversely, CAT, EPI and RES did not decrease the amount of ROS produced by activated macrophages. This indicates that QUE is the most effective modulator of oxidative stress in the long-term.

The large amount of NO produced in response to bacterial lipopolysaccharide plays an important role in endotoxemia and inflammatory conditions (Bellot et al. 1996). Therefore, drugs that inhibit NO generation by inhibiting iNOS expression or its enzyme activity may be beneficial in treating diseases caused by an overproduction of NO (Stoclet et al. 1998). To investigate the effect of polyphenols on NO production, we measured the accumulation of nitrite, the stable metabolite of NO, in culture media. We found a huge NO release by LPS-stimulated cells as opposed to untreated control. The results are in full agreement with the data of others (Shen et al. 2002, Wadsworth and Koop 1999, Wadsworth et al. 2001).

When LPS-activated cells were incubated with QUE or RES, significant and dose-dependent decrease of the NO production was observed after $24 \mathrm{~h}$. It seems likely that QUE and RES inhibit NO production by several mechanisms. Suppression of NO release may be attributed to direct NO scavenging activity, which was previously suggested to be due to their ability to scavenge an exogenous NO donor sodium nitropruside (SNP) in vitro (Chan et al. 2000). Direct NO scavenging activity of studied flavonoids was also proved in our experiments. Another possible mechanism is a modulation of iNOS protein expression. To investigate, whether QUE and RES are able to decrease iNOS protein expression, Western blot analysis of RAW 264.7 exposed to LPS and one of these polyphenols was monitored. As shown in Figure 5, expression of the iNOS protein was not detectable in unstimulated cells, but markedly increased $24 \mathrm{~h}$ after LPS treatment. Treatment with QUE showed a concentration-dependent inhibition of iNOS protein expression in LPS-stimulated RAW 264.7 cells. This finding is in agreement with results of Jung and Sung (2004) who found an inhibitory effect of $5 \mu \mathrm{mol} / 1$ QUE on the expression of iNOS and COX-2 enzymes in lipopolysaccharide-activated RAW 264.7 cells. The results of Kim et al. (1999) indicated that the inhibitory activity of studied flavonoids was not due to direct inhibition of iNOS enzyme activity as measured by $\left[{ }^{3} \mathrm{H}\right]$ citrulline formation from $\left[{ }^{3} \mathrm{H}\right]$ arginine. The regulation of iNOS expression is complex, but appears to occur primarily at the level of transcription. Activation of mitogen-activated protein kinases (MAPKs) and the redox-sensitive transcription factors, nuclear factor- $\kappa \mathrm{B}$ $(\mathrm{NF}-\kappa \mathrm{B})$ and activator protein 1 (AP-1) are key events in the signal transduction pathways mediating iNOS induction in macrophages exposed to LPS (Sherman et al. 1993, Xie et al. 1994). Wadsworth et al. (2001) have found that QUE inhibited p38 MAPK activity and caused the inhibition of iNOS mRNA expression which resulted in decreasing iNOS protein level and NO release in LPSstimulated RAW 264.7 macrophages. It is not clear whether QUE acts more by inhibiting iNOS expression or by direct scavenging of NO. Chan et al. (2000) speculate that QUE and RES may act more by scavenging of NO radicals than by inhibition of iNOS gene expression. The rationale for this deduction is that these compounds were not very effective in reducing iNOS mRNA, while they readily scavenged NO produced by SNP. In our study, inhibition of iNOS protein expression was in parallel with the comparable inhibition of NO production, thus agreeing with the results obtained by Chen et al. (2001), Chan et al. (2000) and Wadsworth et al. (2001). Therefore we propose that the suppression of NO by QUE was mainly mediated by inhibition of iNOS protein expression. As stated earlier, NO plays an important role in the pathogenesis of various inflammatory diseases. Therefore, the inhibitory effect of QUE on iNOS gene expression suggests that this is one of the mechanisms responsible for the anti-inflammatory action of QUE.

Although RES at higher concentrations decreased NO production, it did not influence iNOS expression in LPS-activated RAW 264.7 cells. Our results agree with those of Cho et al. (2002), who found that a higher concentration of RES than needed for the inhibition of NO production was required for the iNOS expression and $\mathrm{NF}-\kappa \mathrm{B}$ translocation. In contrast, resveratrol in a concentration of $30 \mu \mathrm{mol} / 1$ was found to reduce the amount of cytosolic iNOS protein and steady state mRNA levels (Tsai et al. 1999), probably due to 
inhibition of phosphorylation as well as degradation of I $\kappa \mathrm{B} \alpha$ (inhibitory protein bound to $\mathrm{NF}-\kappa \mathrm{B}$ in its unstimulated form in the cytosol), and a reduced nuclear content of NF- $\kappa$ B subunits. Thus, resveratrol (and other polyphenolic compounds) may inhibit the enhanced expression of iNOS in inflammation through downregulation of $\mathrm{NF}-\kappa \mathrm{B}$ binding activity. Bi et al. (2005) reported that despite the inhibition of LPS-induced degradation of I $\mathrm{B} \alpha$, resveratrol may inhibit iNOS expression also via suppression of p38 MAPK in microglial cells. The speculation that RES may act more by scavenging of NO radicals and suppressing the generation of RNS than by the inhibition of iNOS gene expression (Chan et al. 2000, Manna et al. 2000) was not proved in our experiments since RES exhibited only minor NO-scavenging activity in the highest used concentration. Despite that, resveratrol was previously referred to inhibit neutrophil generation of oxidants like superoxide anion and hypochlorous acid (Cavallaro et al. 2003).

In conclusion, this study provides the evidence for in vitro antioxidative effects of wine polyphenols (CAT, EPI, QUE and RES). It seems that the higher number of hydroxyl substituents is an important structural feature of flavonoids (QUE, CAT, EPI) when compared to hydroxystilbenes (RES) in respect to their direct scavenging activity against ROS and RNS while C-2,3 double bond (present in QUE and RES) might be important for inhibition of ROS and NO production. Only QUE significantly decreased the ROS and NO production in LPS-stimulated RAW 264.7 cells in a dose-dependent manner due to its unique chemical structure.

\section{Conflict of Interest}

There is no conflict of interest.

\section{Acknowledgements}

This study was executed within a research plan AVOZ50040507 and was supported by grants of the Grant Agency of the Czech Republic No. 524/04/0897 and the Grant Agency of the Academy of Sciences of the Czech Republic No. B6004204 and 1QS500040507.

\section{References}

ARUOMA OI: Nutrition and health aspects of free radicals and antioxidants. Food Chem Toxicol 32: 671-683, 1994.

BABÁL P, KRISTOVÁ V, ČERNÁ A, JANEGA P, PECHÁŇOVÁ O, DANIHEL L, ANDRIANTSITOHAINA R: Red wine polyphenols prevent endothelial damage induced by $\mathrm{CCl}_{4}$ administration. Physiol Res 55: 245-251, 2006.

BELGUENDOUZ L, FREMONT L, LINARD A: Resveratrol inhibits metal ion-dependent and independent peroxidation of porcine low-density lipoproteins. Biochem Pharmacol 53: 1347-1355, 1997.

BELLOT JL, PALMERO M, GARCIA-CABANES C, ESPI R, HARITON C, ORTS A: Additive effect of nitric oxide and prostaglandin- $\mathrm{E}_{2}$ synthesis inhibitors in endotoxin-induced uveitis in the rabbit. Inflamm Res 45: 203-208, 1996.

BENITO S, BUXADERAS S, MITJAVILA MT: Flavonoid metabolites and susceptibility of rat lipoproteins to oxidation. Am J Physiol 287: H2819-H2824, 2004.

BI XL, YANG JY, DONG YX, WANG JM, CUI YH, IKESHIMA T, ZHAO YQ, WU CF: Resveratrol inhibits nitric oxide and TNF-alpha production by lipopolysaccharide-activated microglia. Int Immunopharmacol 5: 185-193, 2005.

CAVALLARO A, AINIS T, BOTTARI C, FIMIANI V: Effect of resveratrol on some activities of isolated and in whole blood human neutrophils. Physiol Res 52: 555-562, 2003.

CHAN MM, MATTIACCI JA, HWANG HS, SHAH A, FONG D: Synergy between ethanol and grape polyphenols, quercetin, and resveratrol, in the inhibition of the inducible nitric oxide synthase pathway. Biochem Pharmacol 60: $1539-1548,2000$.

CHEN YC, SHEN SC, LEE WR, HOU WC, YANG LL, LEE TJ: Inhibition of nitric oxide synthase inhibitors and lipopolysaccharide induced inducible NOS and cyclooxygenase-2 gene expressions by rutin, quercetin, and quercetin pentaacetate in RAW 264.7 macrophages. J Cell Biochem 82: 537-548, 2001.

CHO DI, KOO NY, CHUNG WJ, KIM TS, RYU SY, IM SY, KIM KM: Effects of resveratrol-related hydroxystilbenes on the nitric oxide production in macrophage cells: structural requirements and mechanism of action. Life Sci 71: 2071-2082, 2002. 
COOK NC, SAMMAN S: Flavonoids - chemistry, metabolism, cardioprotective effects, and dietary sources. $J$ Nutr Biochem 7: 66-76, 1996.

CUENDET M, POTTERAT O, SALVI A, TESTA B, HOSTETTMANN K: A stilbene and dihydrochalcones with radical scavenging activities from Loiseleuria procumbens. Phytochemistry 54: 871-874, 2000.

DELL'AGLI M, BUSCIALA A, BOSISIO E: Vascular effects of wine polyphenols. Cardiovasc Res 63: 593-602, 2004.

FAUCONNEAU B, WAFFO-TEGUO P, HUGUET F, BARRIER L, DECENDIT A, MERILLON JM: Comparative study of radical scavenger and antioxidant properties of phenolic compounds from Vitis vinifera cell cultures using in vitro tests. Life Sci 61: 2103-2110, 1997.

FREMONT L, BELGUENDOUZ L, DELPAL S: Antioxidant activity of resveratrol and alcohol-free wine polyphenols related to LDL oxidation and polyunsaturated fatty acids. Life Sci 64: 2511-2521, 1999.

HUISMAN A, VAN DE WIEL A, RABELINK TJ, VAN FAASSEN EE: Wine polyphenols and ethanol do not significantly scavenge superoxide nor affect endothelial nitric oxide production. $J$ Nutr Biochem 15: 426-432, 2004.

IWAHASHI H: Some polyphenols inhibit the formation of pentyl radical and octanoic acid radical in the reaction mixture of linoleic acid hydroperoxide with ferrous ions. Biochem J 346: 265-273, 2000.

JUNG WJ, SUNG MK: Effects of major dietary antioxidants on inflammatory markers of RAW 264.7 macrophages. Biofactors 21: 113-117, 2004.

KHANDUJA K, BHARDWAJ A: Stable free radical scavenging and antiperoxidative properties of resveratrol compared in vitro with some other bioflavonoids. Indian J Biochem Biophys 40: 416-422, 2003.

KIM HK, CHEON BS, KIM YH, KIM SY, KIM HP: Effects of naturally occurring flavonoids on nitric oxide production in the macrophage cell line RAW 264.7 and their structure-activity relationships. Biochem Pharmacol 58: 759-765, 1999.

LOJEK A, ČIIŽ M, MARNILA P, DUŠKOVÁ M, LILIUS E-M: Measurement of whole blood phagocyte chemiluminescence in the Wistar rat. J Biolumin Chemilumin 12: 225-231, 1997.

LOPEZ M, MARTINEZ F, DEL VALLE C, FERRIT M, LUQUE R: Study of phenolic compounds as natural antioxidants by a fluorescence method. Talanta 60: 609-616, 2003.

MANNA SK, MUKHOPADHYAY A, AGGARWAL BB: Resveratrol suppresses TNF-induced activation of nuclear transcription factors NF-kappa B, activator protein-1, and apoptosis: potential role of reactive oxygen intermediates and lipid peroxidation. J Immunol 164: 6509-6519, 2000.

MIGLIORINI P, CORRADIN G, CORRADIN SB: Macrophage $\mathrm{NO}_{2}{ }^{-}$production as a sensitive and rapid assay for the quantitation of murine IFN-gamma. J Immunol Methods 139: 107-114, 1991.

MOJŽIŠOVÁ G, KUCHTA M: Dietary flavonoids and risk of coronary heart disease. Physiol Res 50: 529-535, 2001.

MOREL I, LESCOAT G, CILLARD P, CILLARD J: Role of flavonoids and iron chelation in antioxidant action. Methods Enzymol 234: 437-443, 1994.

NAKAO M, TAKIO S, ONO K: Alkyl peroxyl radical-scavenging activity of catechins. Phytochemistry 49: 2379-2382, 1998.

OAK MH, EL BEDOUI J, SCHINI-KERTH VB: Antiangiogenic properties of natural polyphenols from red wine and green tea. $J$ Nutr Biochem 16: 1-8, 2005.

OSAWA T: Protective role of dietary polyphenols in oxidative stress. Mech Ageing Dev 111: 133-139, 1999.

RAJDL D, RACEK J, TREFIL L, SIALA K: Effect of white wine consumption on oxidative stress markers and homocysteine levels. Physiol Res 56: 203-212, 2007.

PENDURTHI UR, RAO LVM: Effect of wine phenolics and stilbene analogues on tissue factor expression in endothelial cells. Thromb Res 106: 205-211, 2002.

RICE-EVANS C: Plant polyphenols: free radical scavengers or chain-breaking antioxidants? Biochem Soc Symp 61: 103-116, 1995.

ROBAK J, SHRIDI F, WOLBIS M, KROLIKOWSKA M: Screening of the influence of flavonoids on lipoxygenase and cyclooxygenase activity, as well as on nonenzymic lipid oxidation. Pol J Pharmacol Pharm 40: 451-458, 1988.

SCOTT BC, BUTLER J, HALLIWELL B, ARUOMA OI: Evaluation of the antioxidant actions of ferulic acid and catechins. Free Radic Res Commun 19: 241-253, 1993. 
SHEN SC, LEE WR, LIN HY, HUANG HC, KO CH, YANG LL, CHEN YC: In vitro and in vivo inhibitory activities of rutin, wogonin, and quercetin on lipopolysaccharide-induced nitric oxide and prostaglandin $\mathrm{E}_{2}$ production. Eur J Pharmacol 446: 187-194, 2002.

SHERMAN MP, AEBERHARD EE, WONG VZ, GRISCAVAGE JM, IGNARRO LJ: Pyrrolidine dithiocarbamate inhibits induction of nitric oxide synthase activity in rat alveolar macrophages. Biochem Biophys Res Commun 191: 1301-1308, 1993.

SLAVÍKOVÁ H, LOJEK A, HAMAR J, DUŠKOVÁ M, KUBALA L, VONDRÁČEK J, ČÍŽ M: Total antioxidant capacity of serum increased in early but not late period after intestinal ischemia in rats. Free Radic Biol Med 25: 9-18, 1998.

STOCLET JC, MULLER B, ANDRIANTSITOHAINA R, KLESCHYOV A: Overproduction of nitric oxide in pathophysiology of blood vessels. Biochem-Moscow 63: 826-832, 1998.

TSAI S-T, LIN-SHIAU S-Y, LIN J-K: Suppression of nitric oxide synthase and the down-regulation of the activation of NFKB in macrophages by resveratrol. Br J Pharmacol 126: 673 - 680, 1999.

WADSWORTH TL, KOOP DR: Effects of the wine polyphenolics quercetin and resveratrol on pro-inflammatory cytokine expression in RAW 264.7 macrophages. Biochem Pharmacol 57: 941-949, 1999.

WADSWORTH TL, MCDONALD TL, KOOP DR: Effects of Ginkgo biloba extract (EGb 761) and quercetin on lipopolysaccharide-induced signaling pathways involved in the release of tumor necrosis factor-alpha. Biochem Pharmacol 62: 963-974, 2001.

XIE QW, KASHIWABARA Y, NATHAN C: Role of transcription factor NF-kappa B/Rel in induction of nitric oxide synthase. J Biol Chem 269: 4705-4708, 1994.

YILMAZ Y, TOLEDO RT: Major flavonoids in grape seeds and skins: antioxidant capacity of catechin, epicatechin, and gallic acid. J Agric Food Chem 52: 255-260, 2004. 